\title{
THE EFFECT OF OZONE GEL ON BONE REGENERATION FOLLOWING ENUCLEATION OF MAXILLARY CYSTS
}

\author{
Noha Ahmed Mansour*
}

\begin{abstract}
Introduction: Reconstruction of bony defects represents a challenging problem for the surgical community. ozone therapy seems to be a promising future in different dental modalities that may be effective in treating bony defects.
\end{abstract}

Objectives: The aim of this study was to assess the effect of topical ozone gel application on bone regeneration following enucleation of maxillary cysts.

Materials and methods: After surgical enucleation of odontogenic maxillary cystic lesions in sixteen patients, eight bony defects were grafted with ozone gel; the second group served as controls. Computed multi-slice CT scans were obtained immediately after surgery, -6 and -9 months post-surgery to assess the decrease in bone defect size and density of newly formed bone.

Results: The study group showed significant increase in bone density of newly formed bone at $6 \& 9$ months postsurgical $(\mathrm{p}=0.039,0.042)$ and significant decrease in bone defect size as it recorded a mean percentage of residual area of bone defect in axial cuts $39.46 \pm 9.17,22.52 \pm 7.02$ while control group recorded a mean of $64.08 \pm 9.88,49.74 \pm 10.96$ at $6 \& 9$ months respectively.

Conclusions: Ozone gel can be considered a healing biomaterial, as it features all the necessary parameters permitting bone regeneration without any adverse reaction. It gives a predictable clinical and radiographic evidence of bone formation and faster healing than control group.

KEYWORDS: bone regeneration, maxillary cyst, ozone.

\section{INTRODUCTION}

Odontogenic cysts are one of the most frequent pathologies in maxillofacial surgery which can occur during every period of life. The cysts are usually characterized by a small and asymptomatic growth, which mostly results in large bone cavities. ${ }^{(1)}$ Tra- ditionally, the enucleation of odontogenic cysts has been the standard method of treatment. The enucleation of cysts directly involves the removal of the cystic walls completely, considering the size, location, pathological diagnosis, and anatomical structures of the lesions. ${ }^{(2)}$

* Lecturer of Oral Surgery, Department of Oral and Maxillofacial Surgery, Faculty of Dentistry, Mansoura University, Mansoura, Egypt. 
Although the bone tissue has a unique ability to restore its original structure completely after injuries. However, such large defects may not regenerate spontaneously and require the use of surgical or pharmacological measures for complete and faster regeneration. ${ }^{(3)}$ As a result, a range of bone graft materials and osteogenic factors have been investigated but have not led to ideal alternatives or substitutes, so relevant studies are ongoing.

In recent years, there has been a growing concern in biological augmentations utilized for bone healing. Ozone (O3) is a natural gaseous molecule made up of three oxygen atoms. it is a very reactive gas, but it can be dissolved in the blood at appropriate doses and stimulates important molecular, biochemical, and pharmacological pathways. ${ }^{(4)}$

Ozone can be applied in three forms: oxygen/ ozone gas, ozonated oil/gel, ozonated water. Ozonated oil/gel can entrap ozone and then release it when in contact with a lesion. ${ }^{(5)}$ Ozonated oils are obtained using ozone generators which regulate the flow of medical grade $\mathrm{O} 2$ to produce pure ozoneoxygen mixtures in precise dosages. ${ }^{(6)}$

Ozone acts as a super-oxygenator, bringing oxygen to tissues, assisting the body in its natural healing process. The effect of $\mathrm{O} 3$ is through promoting hemostasis and enhancing the release of growth factors. In addition, it can stimulate immune responses and blood circulation. ${ }^{(7,8)}$

Ozone is popular with its anti-inflammatory and analgesic action; it helps in the synthesis of biologically active substances such as interleukins, leukotrienes and prostaglandins which is valuable in reducing inflammation and pain. Furthermore, it has been shown to be a powerful and reliable anti-microbial agent against bacteria, fungi, protozoa, and viruses. ${ }^{(9,10)}$

It is claimed to have a bio-energetic and biosynthetic action as it activates mechanisms of protein synthesis, increases number of ribosomes and mitochondria in cells, enriching functional activity and regeneration potential of tissues and organs. ${ }^{(11)}$

Recently Ozone therapy gained access to the field of dentistry in many approaches, such as the management of early carious lesions and ulcerations, the sterilization of root canals, and periodontal pockets, ozonated water used as a coolant for burrs and for rinsing wounds. ${ }^{(12-15)}$ However, there is insufficient evidence in the application of ozone in oral and maxillofacial surgery. As ozone has a therapeutic effect that facilitates wound healing and improves the supply of blood and growth factors, ozone therapy could enhance bone regeneration. To the best of our knowledge, the effect of local ozone therapy on alveolar bone regeneration after surgical management of intrabony lesions has not yet been evaluated scientifically. The aim of this clinical study was to assess the effect of ozone gel on bone regeneration after surgical enucleation of maxillary odontogenic cysts.

\section{MATERIALS AND METHODS}

Sixteen patients diagnosed with maxillary cysts, referred to Oral Surgery Department, Faculty of Dentistry, Mansoura University were involved in this study. The study followed the declaration of Helsinki of medical protocol and ethics. All patients were informed about the nature of the study and signed a written consent with full rights to quit the study at any time.

Patients were divided into two equal groups. In the first group after cystic enucleation\& apicectomy of related teeth, the resultant bony defects were grafted with ozone gel. In the second group the resultant bony defects were left empty to heal spontaneously.

\section{Inclusion criteria}

- Patients of both sexes with different ages ranged from (18-40) years old, having maxillary cystic 
lesions bigger than $1.5 \mathrm{~cm}$ in diameter, could be treated by surgical enucleation.

\section{Exclusion criteria ${ }^{(16)}$}

- Systemic diseases that may compromise bone healing as osteoporosis, uncontrolled diabetes mellitus, history of chemotherapy or radiotherapy, haematological disorder, patients under anticoagulant therapy or long-term medication drugs (e.g., Corticosteroids) that have a direct bearing on bone maintenance.

- Infection at the surgical site.

\section{Material}

Ozone gel: (Ozene; Premier Research Labs, 3500-b Wadley pl, Austin, TX, USA. 78728) composed of a mixture of oxygen and ozone in ratio of $0.25 \%$ and $99.75 \%$ respectively, and unoxidized olive oil.

\section{A-Preoperative phase:}

- After through history and intra-oral examination, pre-operative panoramic X-ray films or maxillary CT scan were evaluated to determine the extension of lesion, its relation to nose or maxillary sinus and the number of teeth needing apicectomy.

- Endodontic treatment was performed for the indicated teeth before surgery.

\section{B-Operative procedure:}

- The procedure was performed under complete aseptic conditions, the surgical field was swabbed with povidone Iodine solution (Betadine ${ }^{\circledR}$, Nile Company for Pharm., Chemical IND., Cairo).

- All patients were operated under local anaesthesia $2 \%$ mepivacaine hydrochloride with 1:20,000 levonordefrine (Mepicaine-L carpule ${ }^{\circledR}$, A product of Alexandria Company for Pharmaceutics and chemical Industries, Alex- andria) by standard nerve block and infiltration anaesthesia.

- Surgical procedure followed the standard steps of surgical enucleation of odontogenic cysts; A full thickness pyramidal mucoperiosteal flap, depending on lesion extent, was incised and reflected to expose the underlying bone (fig.1a). The non-healthy bone was removed using either sharp cutting bone rongeur or surgical rose head bur with sterile saline cooling until exposing the root apices. The cyst lining was wholly removed using large curette and the root apices of the affected teeth were amputated (fig.1b). The margins of the resultant cavity were filed by a surgical file to smooth the sharp bony margins. The bony defect was washed with normal sterile saline solution using a $5 \mathrm{~cm}$ sterile plastic syringe. High suction was employed to render the field some dry. Finally, a large sterile gauze pack was placed into the bony defect to keep it dry.

- For study group, bone defects were filled with ozone gel using sterile plastic syringe, while bone defects in the control group were left empty (fig.1c, d\& e).

- The mucoperiosteal flap was then repositioned to its original place and sutured using 3/0 blacksilk and a sterile surgical cutting needle (fig.1f). Finally, a gauze pack was placed to cover the wound.

\section{Postoperative instructions and medications:}

- Use cold packs extra-orally first day after operation.

- Avoid hot drinks and hot food for 24 hours, soft diet of high calories was recommended.

- Avoid smoking for 48 hours.

- Avoid mouth washes for 24 hours.

- Motivation and maintaining the oral hygiene and using soft toothbrush regularly. 


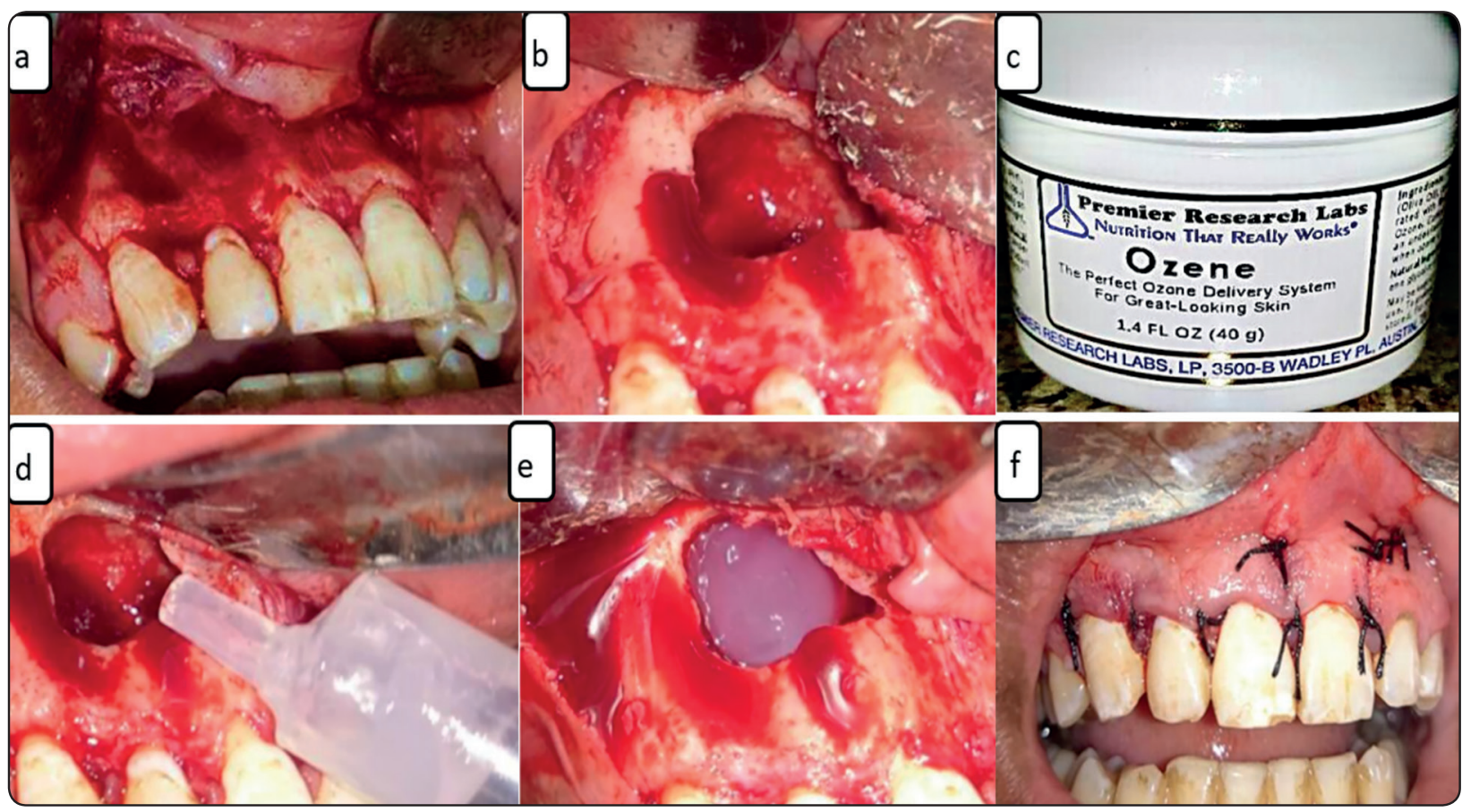

Fig. (1) Photograghs showing surgical procedures for enucleation of a maxillary cyst and application of ozone gel. a; Reflection and retraction of full mucoperiosteal flap. b; Bone cavity after cystic enucleation and apicectomy of related teeth. c; Ozone gel (Ozene ${ }^{\circledR}$ ) used to fill the bony defect after enucleation. d; Loading of a plastic syringe with ozone gel. e; The bone cavity filled with ozone gel.f; Repositioning and suturing of flap.

- Patients were informed to return after 7-10 days for sutures removal.

- Postoperative mouth wash, antibiotic and analgesic drugs were described as follow;

- Antibiotic: Amoxicillin-Clavulanic acid (Hibiotic ${ }^{\circledR}$, Amoun pharmaceutical CO. S.A.E. - Egypt) (1 GM/12 hours) was prescribed for 5 days post-operatively.

- Analgesic: diclofenac potassium (Cataflam ${ }^{\circledR}$, Novartis, Switzerland) (50 mg/12 hours) prescribed for 3 days.

- Mouthwash: patients were instructed to use chlorohexidine mouth wash (Hexitol® mouth wash: by Arab drug company, Cairo, Egypt.) twice daily for one week, starting on the 2nd day post-operative.

\section{Postoperative Evaluation:}

\section{1- Clinical evaluation:}

Clinical evaluation was based on subjective symptoms and clinical examination, to determine any signs of inflammation, swelling, infection, pain, tissue dehiscence, or graft rejection.

\section{2- Radiographic evaluation: ${ }^{(2,17,18)}$}

Radiographic evaluation was done immediately after surgery then 6 and 9 months post surgically by computed multislice maxillary CT scan (Philips Brilliance ${ }^{\mathrm{TM}} \mathrm{CT}$ ) using a low dose protocol of the affected jaw.CT scans were exported as DICOM files and transferred to a custom research workstation.

The CT taken immediately after surgery served to establish a starting point to calculate the reduction in bone defect size \& a quotient of relative densities 
of newly formed bone and the contra lateral normal bone at $6 \& 9$ months post surgically.

\section{Area of bone defect (BD)}

- For each patient, the area of the bony cavity was measured by computerized software in reconstructed axial and coronal CT radiograph immediately postoperative, and then at 6 \& 9 months post-surgical. At each time the measurement was done using bone window in the central radiographic cut which shows the largest bone defect dimensions. (fig. 2\&3)

- Percent of residual area of bone defect was calculated as the quotient of residual area at taken time \& area taken immediately after surgery.
- (Relative area of bone defect $=100 \times$ residual area of $\mathrm{BD}$ at taken time/area taken immediately.)

- Percent of bone regeneration was calculated statistically as the ratio of decrease in bone defect area $=100 \times($ bone defect area immediately after surgery- bone defect area at taken time) / bone defect area immediately after surgery.

\section{Density of augmented area}

- Bone density of newly formed bone within bone defect area was measured in the original axial CT cuts in Hounsfield units at 6 \& 9 months post surgically. Three areas were determined in each BD to measure bone density then the mean value was recorded to diminish errors.

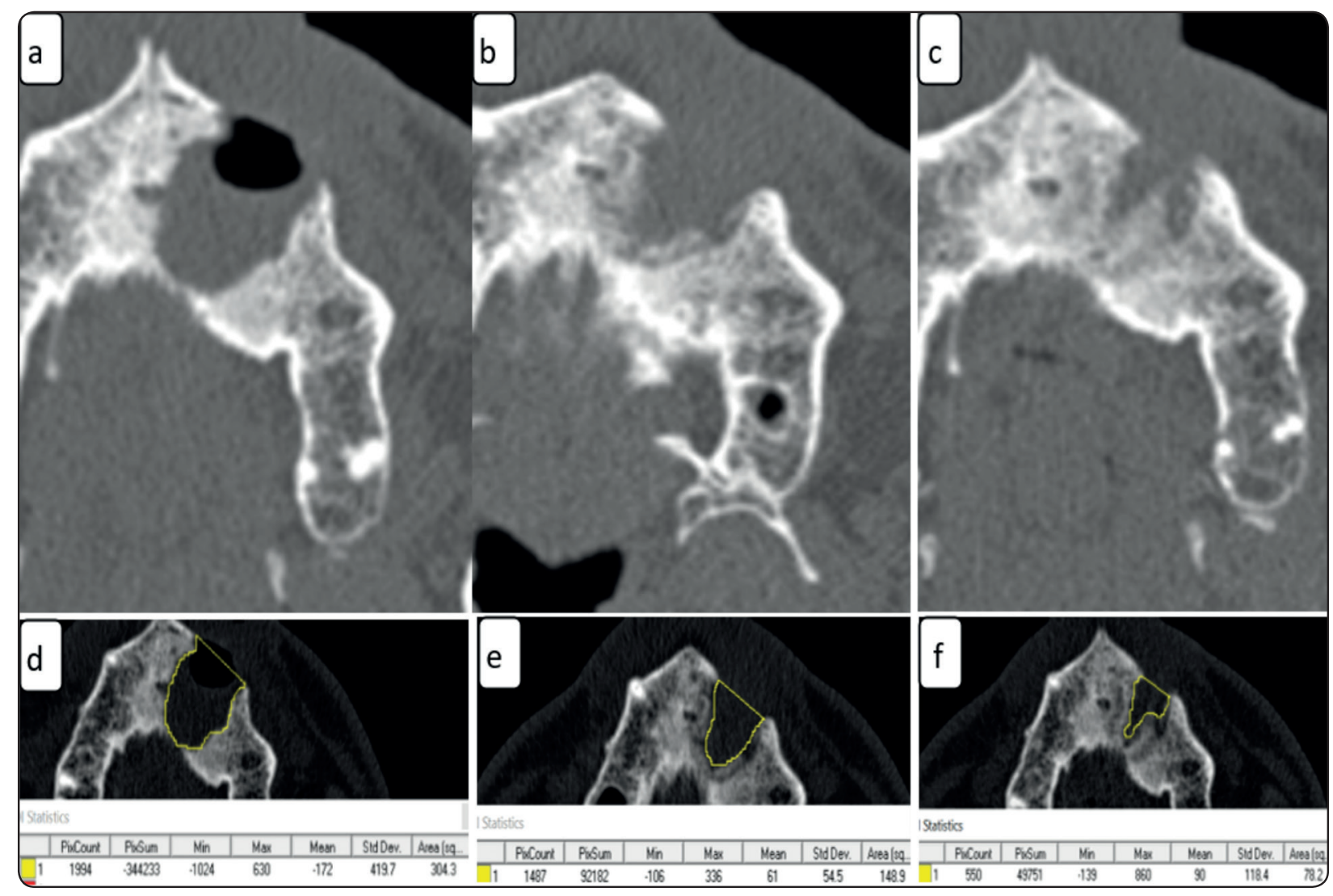

Fig. (2) : CT cuts of a study case; showing maxillary bone defect after cystic enucleation and ozone gel application: a) Axial cut immediately after surgery. b) Axial cut 6-months after surgery. c) Axial cut 9-months after surgery. d) Bone window of axial cut showing measurement of bone defect area immediately post-surgery. e) Bone window of axial cut showing measurement of bone defect area 6-months post-surgery. f) Bone window of axial cut showing measurement of bone defect area 9-months post-surgery. 


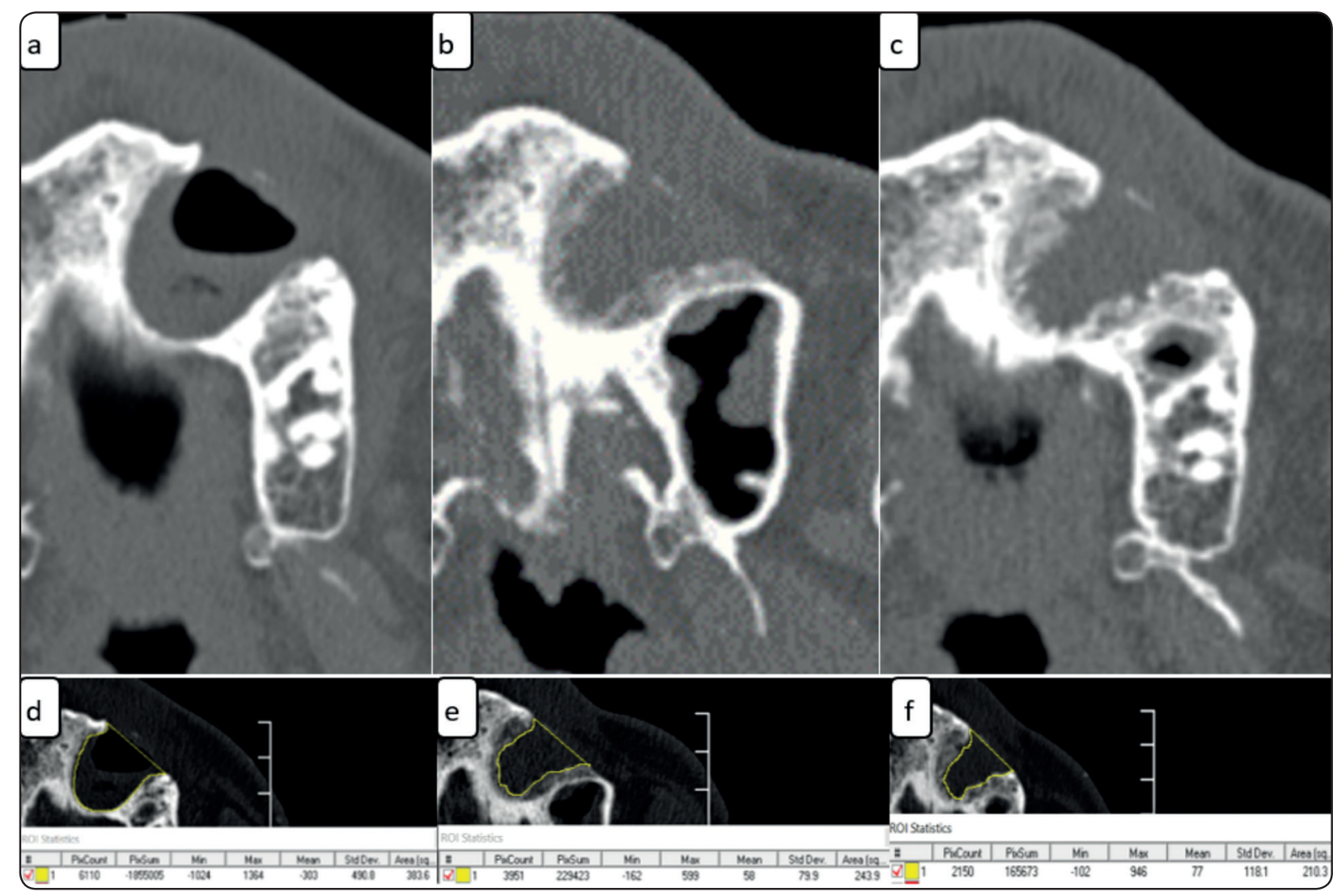

Fig. (3) : CT cuts of a control case; showing maxillary bone defect after cystic enucleation: g) Axial cut immediately after surgery. h) Axial cut 6-months after surgery. i) Axial cut 9-months after surgery. j) Bone window of axial cut showing measurement of bone defect area immediately post-surgery. k) Bone window of axial cut showing measurement of bone defect area 6-months post-surgery. 1) Bone window of axial cut showing measurement of bone defect area 9-months post-surgery.

- In the same way the mean value for bone density of the contra lateral normal bone was recorded. Percentages of relative bone density were calculated as the quotients of mean bone density in the $\mathrm{BD}$ and the mean bone density of the contra lateral normal bone at 6- and 9-months post surgically.

\section{Statistical analysis}

The Statistical Package of Social Science (SPSS) program for Windows (Standard version 21) was used for data analysis. Number and percent were used to describe qualitative data. For normally distributed data, continuous variables were presented as mean $\pm \mathrm{SD}$ (standard deviation). Collected data were statistically analyzed using independent T-test to compare the two groups with a $\mathrm{P}$ value $<0.05$ considered as statistically significant.

\section{RESULTS}

Sixteen subjects (7 males and nine females) participated in this study; the study group included 8 patients ranging in age from 19 to 39 years with a mean age of 27.62 years. The control group included 8 patients ranging in age from 18 to 40 years with a mean age of 26.25 years. No statistically significant difference was found between the two groups as regard sex or age $(\mathrm{p}=0.7)$ All patients had undergone surgical enucleation of an odontogenic maxillary cyst followed by clinical evaluation and radiological evaluation using spiral CT scan. 


\section{Clinical evaluation}

Other than the normally expected post-surgical pain and swelling, no patient had complaint of unusual or severe pain throughout the study period. During the healing phase of both groups, no evidence of inflammation, bleeding, wound dehiscence, or signs of infection in or around the wound site could be detected. All mucosal incisions healed by primary intention within 7-10 days. In the study group, no adverse post-operative complications or rejection had been reported.

\section{Radiological evaluation}

For ozone group, mean area of bone defects immediately postsurgical was $259.15 \pm 61.65$ in axial view, 205.25 \pm 58.52 in coronal view. In the control group, it was $293.84 \pm 69.90$ in axial view, $246.05 \pm$ 66.69 in coronal view as shown in table 1 . There was no significant difference between the two groups in relation to area of bone defect in both axial \& coronal views. $(\mathrm{P}=0.31,0.21)$

As regard relative areas of bone defects postsurgical; means \pm SD in axial view at 6 and 9 months were $39.46 \pm 9.17 \%$ and $22.52 \pm 7.02 \%$ for ozone group, while in the control group they were $64.08 \pm 9.88 \%$ and $49.74 \pm 10.96 \%$ respectively. There was statistically significant difference between the 2 groups at 6 and 9 months postsurgical $(\mathrm{P}<.001)$.
TABLE (1): Area of bone defects (mm2) immediately postsurgical in axial and coronal views for study and control groups.

\begin{tabular}{lcc}
\hline & $\begin{array}{c}\text { Area of bone } \\
\text { defect } \\
\text { (Axial view) }\end{array}$ & $\begin{array}{c}\text { Area of bone } \\
\text { defect } \\
\text { (Coronal view) }\end{array}$ \\
\hline Study group & $259.15 \pm 61.65$ & $205.25 \pm 58.52$ \\
Mean \pm SD & $180.8-342$ & $135-295.2$ \\
Min-Max & & \\
\hline Control group & $293.84 \pm 69.90$ & $246.05 \pm 66.69$ \\
Mean \pm SD & $200-387$ & $152.9-345$ \\
Min-Max & 0.31 & 0.21 \\
\hline$P$ value (significant & & \\
at $\mathrm{p}<.05)$ & & \\
\hline
\end{tabular}

In coronal view, means $\pm \mathrm{SD}$ at 6 and 9 months were $35.81 \pm 6.70 \%$ and $22.08 \pm 5.49 \%$ for ozone group, while in the control group they were $61.61 \pm 5.94$ and $48.73 \pm 9.46 \%$ respectively with statistically significant difference between the 2 groups at 6 and 9 months $(P<.001)$ as shown in table $2 \&$ figure 4 .

Mean percentage of bone regeneration was calculated statistically in ozone group at 6 months as $60.54 \pm 9.17 \%$ in axial view and $64.19 \pm 6.70 \%$ in coronal view with a statistical mean of $62 \%$, after 9 months it was $77.475 \pm 7.02$ in axial view and $77.93 \pm 5.49 \%$ in coronal view with a mean of $77.7 \%$. In control group, it was $35.93 \pm 9.88 \%$ in TABLE (2): Percentages of residual areas of bone defects (BD) in axial\& coronal views at $6 \& 9$ months postsurgical.

\begin{tabular}{lcccc}
\hline & $\begin{array}{c}\text { Residual axial (BD) } \\
\text { area at } \mathbf{6 m}(\mathbf{\%})\end{array}$ & $\begin{array}{c}\text { Residual axial (BD) } \\
\text { area at } \mathbf{9 m}(\boldsymbol{\%})\end{array}$ & $\begin{array}{c}\text { Residual coronal (BD) } \\
\text { area at } \mathbf{6 m}(\boldsymbol{\%})\end{array}$ & $\begin{array}{c}\text { Residual coronal (BD) } \\
\text { area at 9m }(\%)\end{array}$ \\
\hline $\begin{array}{l}\text { Study group } \\
\text { Mean } \pm \text { SD }\end{array}$ & $39.46 \pm 9.17$ & $22.52 \pm 7.02$ & $35.81 \pm 6.70$ & $22.08 \pm 5.49$ \\
Min-Max & $28.1-51$ & $14.2-34$ & $23.4-44$ & $15.2-31$ \\
\hline Control group & & & $61.61 \pm 5.94$ & $48.73 \pm 9.46$ \\
Mean \pm SD & $64.08 \pm 9.88$ & $49.74 \pm 10.96$ & $52.9-71.1$ & $36-61.7$ \\
Min-Max & $42.9-72.5$ & $35.8-62.7$ & $<0.001$ & $<0.001$ \\
\hline Unpaired t-test & $<0.001$ & $<0.001$ & & \\
$P$ significant at $\mathrm{p}<.05$ & & & & \\
\hline
\end{tabular}




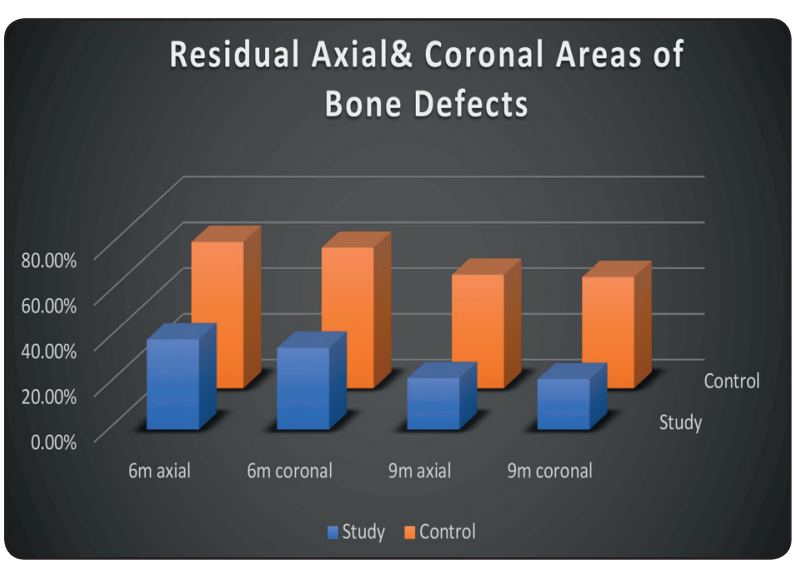

Fig. (4): Mean percentages of residual areas of bone defects in axial and coronal views after 6 and 9 months.

axial view and $38.39 \pm 5.94$ in coronal view with a mean of $37.16 \%$, after 9 months it was $50.26 \pm$ $10.96 \%$ in axial and $51.27 \pm 9.46 \%$ in coronal view with a mean of $50.77 \%$. A statistically significant difference was found between the two groups at 6month $(P<.001)$, and 9 months $(P<.001)$. Means of bone regeneration were shown in figure 5 .

Means of density of newly formed bone within bone defects after $6 \& 9$ months recorded as 182.7 , 286.5 HU for ozone group and 117.6, $192 \mathrm{HU}$ for control group. By calculating percent of bone density relative to contralateral bone; it was $48.4 \%$, $73 \%$ for ozone group and $36 \%, 57.2 \%$ for control group at $6 \& 9$ months respectively with a statistical significant difference between the two groups $(\mathrm{p}=0.03,0.04)$ as shown in table 3 and figure 6 .

TABLE (3): Relative bone density after $6 \& 9$ months for study\& control groups.

\begin{tabular}{lcc}
\hline & \multicolumn{2}{c}{$\begin{array}{c}\text { Relative Bone Density } \\
(\%)\end{array}$} \\
\cline { 2 - 3 } & $\mathbf{6 m}$ & $\mathbf{9 m}$ \\
\hline Study group & & \\
Mean \pm SD & $48.36 \pm 10.21$ & $73.09 \pm 12.45$ \\
Min-Max & $39.5-69.8$ & $57.2-93.3$ \\
\hline Control group & $36.03 \pm 11.48$ & $57.26 \pm 15.77$ \\
Mean \pm SD & $23.45-56.07$ & $37.56-80.62$ \\
Min-Max & 0.039 & 0.042 \\
\hline P value & & \\
(Significant at $\mathrm{p}<.05)$ & & \\
\hline
\end{tabular}

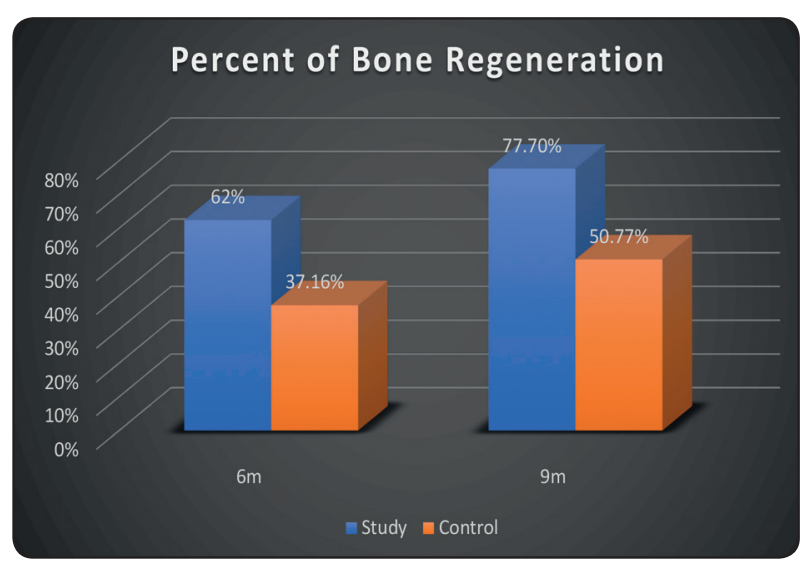

Fig. (5): Mean percentages of bone regeneration after $6 \&$ 9 months for study\& control groups.

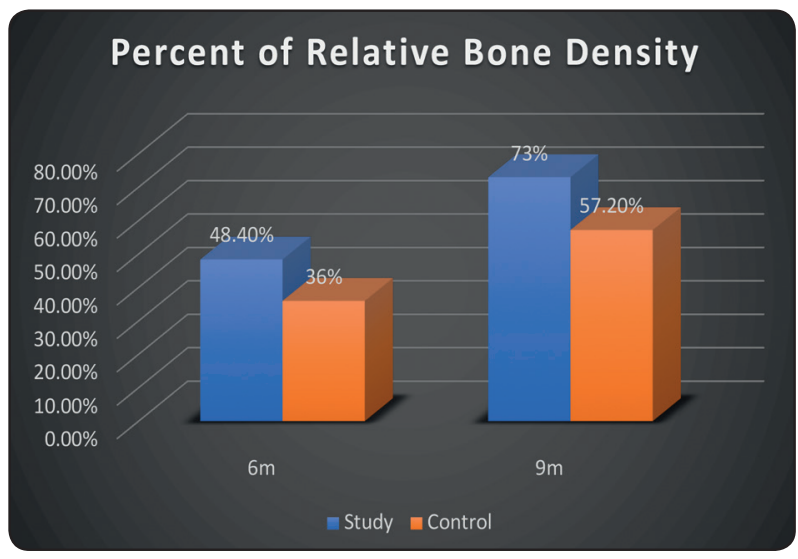

Fig. (6): Mean percentages of relative bone density after $6 \&$ 9 months for study\& control groups.

\section{DISCUSSION}

Bone healing and regeneration to normal form and function is the ultimate goal after surgical management of intra-bony pathological lesions. Odontogenic cysts are common lesions of the jaw, and the therapeutic approach is the complete enucleation, which results in a bone defect. ${ }^{(19)}$ Because such defects require faster healing and complete reconstruction to achieve functional and esthetic recovery, numerous studies and different strategies of bone grafting have been undertaken to fulfill these requirements.

However, there are associated obstacles and restrictions to their use and availability, and even 
controversial reports about their efficacy and cost-effectiveness. Moreover, at present there are no available synthetic bone substitutes that have superior or even the same biological or mechanical properties compared with bone. Therefore, there is a need to develop novel treatments as alternatives or adjuncts to the standard methods used for bone regeneration, in an effort to overcome these limitations. ${ }^{(20)}$

The aim of this study was to evaluate the effect of local application of ozone gel on bony regeneration after surgical enucleation of large maxillary cysts by postoperative 3D image assessments.

Ozone delivery system can provoke several responses on the biological aspect of bone regeneration, such as improvement of the blood circulation in ischemic tissue by increasing oxygen delivery and enhancement of the general metabolism via mild activation of the immune system and upregulation of cellular antioxidant enzymes and growth factors. ${ }^{(21)}$ Owing to its properties it could be promising in treating bone defects.

Gel form was chosen for local application in this study as it is easily applied, eliminates the need of complex armamentarium for its production and storage and contains accurate dosage of ozone molecules that are stable for longer duration and has a life span that could be measured in years. ${ }^{(22,23)}$

The assessments in the current literature were based on measuring the percentage changes in the bone defect size and the percentage of bone density of newly formed bone within the defect using CT scan. This agrees with different studies conducted over the years that have evaluated the degree of bone regeneration after cystic enucleation by measuring the maximum diameters of the residual cavities at different time intervals. ${ }^{(24)}$

Studies in the past have used panoramic radiography to evaluate volumetric changes in cysts. Certainly, with panoramic radiography, patients are less exposed to radiation; however, it is a two-dimensional analysis method, so it is less accurate in determining the exact volumetric variations. ${ }^{(25)}$

All patients included in this study were free from any systemic disease or taking drugs affect bone healing process, their age, sex, and sizes of bone defects immediately postsurgical were insignificantly different between the study and control groups indicating that the bone healing was comparable for all the patients.

The radiographic results of this study showed significant less means of bone defects sizes in ozone group after $6 \& 9$ months, indicating that ozone gel produced more new bone than the control group with a mean percentage of $62 \%$ and $77.7 \%$ at 6 and 9 months postsurgical, while in the control group means of bone regeneration percentages were $37.16 \%$ and $50.77 \%$ respectively.

Findings of the current study revealed an obvious enhancement in new bone formation of the ozone gel treated bone defects. This result is in agreement with various experimental studies assessed ozone application in induced bone defects.

Ozdemir et al. (26) found similar results of increase bone healing when utilized ozone gel in calvaria of rats in terms of increase osteoblast number and new bone formation, both in histomorphometric assessments and histological analyses. In another animal study, the application of oxygen-ozone therapy appeared to stimulate bone regeneration, with a concentration of $25 \mu \mathrm{g} / \mathrm{mL}$ confirming to be the most efficient dose. ${ }^{(27)}$

Laçin $\mathrm{N}$ et al ${ }^{(28)}$ showed that the best result for new bone formation in calvarial bone defects was obtained by adding ozone to bone graft. It is concluded that ozone application increases the hemostasis in the region, promotes osteoblastic activity and matrix formation and has a positive effect on angiogenesis and osteogenesis.

In the same context, Erdemci et al ${ }^{(29)}$ reported significant improve in alveolar bone healing by using systemic ozone treatment after tooth extraction in 112 wistar rats. Irban A et al ${ }^{(30)}$ proved the posi- 
tive effect of ozone therapy on experimental bone fracture healing in rats

In contrast with our results, Kotze et al ${ }^{(31)}$ in 2014 found that there is a lack of evidence of the effect of ozone on alveolar bone regeneration in baboon. However, they used a single concentration and a single dose of $\mathrm{O} 3$ for one minute.

Our results are in concordance with the studies evaluated the effect of ozone application in the periodontium; Nagayoshi et al ${ }^{(32)}$ reported that the ozone has a marked anti-inflammatory effect, reducing oral micro-organisms, and decreasing the pocket depth. Another study ${ }^{(33)}$ concluded that the topical application of ozone has led to a significantly advance in clinical attachment and enhanced bone tissue formation restoring the lost and destructed periodontal tissues. Holmes ${ }^{(34)}$ proved the same results showing that ozonized oil could stimulate the reparative cellular mechanisms.

As regard relative density of new formed bone in relation to contra lateral normal bone, there was statistically significant difference between the 2 groups at 6 and 9 months postsurgical $(\mathrm{p}=0.039$, 0.042). The faster bone healing of the grafted area, as indicated by the more rapid density increase, is a result of the implanted material.

This improvement in bone density was in agreement with a study assessed the using of ozone gel inside mandibular bony defects in dogs and revealed increase in bone density and also increasing of vascularity in the study group than in the control group. ${ }^{(35)}$ In an in vivo study of rabbits, El Hadary et al (36) noted that ozonated oil topical application could affect both bone density and the quality of osseointegration around dental implants.

Although some studies ${ }^{(37,38)}$ proved effectiveness of local application of ozone in increasing patient comfort and decreasing post-operative sequalae after surgical impaction therapy, rare clinical studies in literature conducted on patients to assess effect of ozone on bone regeneration after oral surgical procedures.
Results of this study are in accordance with Agrillo et al. ${ }^{(39)}$ who studied the effect of topical ozone gas on wound healing after tooth extraction in 15 patients using bisphosphonates. Clinical and radiological follow-ups of patients showed full recovery in the extraction sockets.

In 2018 Pulga $\mathrm{A}^{(40)}$ report the case of a 69 -yearold patient, for whom oxygen-ozone therapy was utilized as a treatment that could diminish the bone resorption of the alveolar ridges after tooth extraction for implant placement. He reported that the results exceeded greatest expectations, given that the measurements even showed an increase in bone peaks.

M.S Matar $\mathrm{I}^{(41)}$ study showed that Ozone therapy accelerated and enhanced the osseointegration of titanium implants; increasing bone density in peri-implant interface and reducing the anticipated marginal bone loss in eight patients.

This tremendous regenerating ability of Ozone gel may be due to the potential of ozone to induce the production of cytokines known for their outstanding healing and regenerative functions. This theory is in accordance with Bocci $\mathrm{V}^{(42)}$ who reported that ozone stimulates the immune system to produce more white blood cells, and many cytokines such as bone morphogenic protein, interferon, interleukin-2, and tumor necrosis factor. These cytokines are of crucial values for bone healing enhancement. ${ }^{(43)}$

In addition, ozone was found to increase the circulation even through the ischemic tissues, supplying tissues with nutrients, oxygen, and inflammatory cytokines needed for healing, furthermore, increases washing action of the waste products out of the tissues and it increases the oxygen carrying capability of the red blood cells. ${ }^{(44)}$

Finally, no adverse reactions were recorded during the period of follow up. The results of this study show that topical ozone gel application accelerates and enhances bone regeneration after surgical enucleation of maxillary cysts in terms of quantity and quality. 


\section{CONCLUSION}

Using ozonated gel for bone regeneration in the treatment of osseous defects resulted after surgical enucleation of intra-bony odontogenic cysts accelerates bone healing and increases density of newly formed bone. Owing to its various properties, cost effectiveness and ease of application, ozone gel should be considered as a new therapeutic modality of great benefits in oral and maxillofacial surgery.

\section{REFERENCES}

1. Buchbender M, Koch B, Kesting MR, Matta RE, Adler W, Seidel A, Schmitt CM. Retrospective 3D analysis of bone regeneration after cystectomy of odontogenic cysts. J Xray Sci Technol. 2020; 28(6):1141-1155.

2. Vitale $A$, Battaglia $S$, Crimi $S$, Ricceri $C$, Cervino $G$, Cicciù M, De Ponte F.S, Leonardi R.M, Bianchi A. Spontaneous Bone Regeneration after Enucleation of Mandibular Cysts: Retrospective Analysis of the Volumetric Increase with a Full-3D Measurement Protocol. Appl. Sci. 2021; 11: 4731.

3. Giannoudis P \& Calori G \& Bégué T \& Schmidmaier G. Bone regeneration strategies: Current trends but what the future holds? Injury, Int. J. Care Injured. 2013; 44: S1-S2.

4. Gurger M, Once G, Yilmaz E, Demir S, Calik I, Say Y, Kavakli A, Key S, Gurbuz MU, Bingollu O. The effect of the platelet-rich plasma and ozone therapy on tendon-to-bone healing in the rabbit rotator cuff repair model. J Orthop Surg Res. 2021; 16(1):202.

5. Bianco E, Maddalone M, Porcaro G, Amosso E, Baldoni M. Treatment of Osteoradionecrosis of the Jaw with Ozone in the Form of Oil-based Gel: 1-year follow-up. J Contemp Dent Pract. 2019; 20(2): 270-276.

6. Ugazio E, Tullio V, Binello A, Tagliapietra S, Dosio F. Ozonated Oils as Antimicrobial Systems in Topical Applications. Their Characterization, Current Applications, and Advances in Improved Delivery Techniques. Molecules. 2020; 25(2): 334.

7. Kumar A, Bhagawati S, Tyagi P, Kumar P. Current interpretations and scientific rationale of the ozone usage in dentistry: A systematic review of literature. Eur J Gen Dent 2014; 3: 175-80.

8. Duman IG, Davul S, Gokce H, Gonenci R, Özden R, Uruc $\mathrm{V}$. Effects of gaseous ozone treatment on bone regeneration in femoral defect model in rats. J Hard Tissue Biol. 2017; 26: 7-12.
9. Gonzadez ML, Fernandez AJ, Ali AJ, Moscardo AP, Diago PM A. Effect of Ozone therapy upon clinical and bacteriological parameters of oral cavity: an update. J Clin Exp Dent 2011; 3: 325-7.

10. Naik SV, K R, Kohli S, Zohabhasan S, Bhatia S. Ozone- A Biological Therapy in Dentistry- Reality or Myth? Open Dent J. 2016; 10: 196-206.

11. Baysan A, Lynch E. The use of ozone in dentistry and medicine. Part 2. Ozone and root caries. Prim Dent Care 2006; 13: 37-41.

12. Azarpazhooh A. and Limeback H. The application of ozone in dentistry: a systematic review of literature. J Dent 2008; 36: 104-116.

13. Baysan A. and Lynch E. Effect of ozone on the oral microbiota and clinical severity of primary root caries. Am J Dent 2004; 17: 56-60.

14. Kshitish D, Laxman VK. The use of ozonated water and $0.2 \%$ chlorhexidine in the treatment of periodontitis patients. A clinical and microbiologic study. Indian J Dent Res 2010; 21: 341-8.

15. Zimmermann D, Waltimo T, Filippi A. Ozonized water in dental traumatology - a pre- liminary study on the treatment of avulsed teeth, in vitro. Ozone Sci Eng 2012; 34:484-8.

16. Zain Elabdin, A., Sharara, A., Ragab, H. The effect of platelet rich-fibrin with and without autogenous bone graft on bone regeneration following enucleation of maxillary cysts. Alexandria Dental Journal, 2020; 45(3): 1-6

17. Ihan Hren N, Miljavec M: Spontaneous bone healing of the large bone defects in the mandible. Int J Oral Maxillofac. surg, 2008; 37:1111-1116.

18. Demir E and Günhan O. Treatment Results of Dentigerous Cysts Managed by Marsupialisation, Enucleation or Enucleation with Platelet Rich Plasma-a Retrospective Study. Meandros Med Dent J 2021; 22:116-24

19. Raţiu CA, Raţiu IA, Cavalu S, Boşca AB, Ciavoi G. Successful management of spontaneous bone regeneration after jaws cystectomy using PRGF approach; case series. Rom J Morphol Embryol. 2020; 61(3): 833-840.

20. Dimitriou R, Jones E, McGonagle D, \& Giannoudis PV. Bone regeneration: current concepts and future directions. BMC Medicine, 2011; 9: 66

21. Sagai M. and Bocci V. Mechanism of action involved in ozone therapy: Is healing induced via a mild oxidative stress? Med Gas Res. 2011; 20: 1-29. 
22. Gupta G, Mansi B. Ozone therapy in periodontics. J Med Life. 2012; 5: 59

23. Sechi LA, Lezcano I, Nunez N, Espim M, Duprè I, Pinna A, Molicotti P, Fadda G \& Zanetti S. Antibacterial activity of ozonized sunflower oil (Oleozon). Journal of Applied Microbiology. 2001; 90: 279-284.

24. Chacko R, Kumar S, Paul A, Arvind A. Spontaneous Bone Regeneration after Enucleation of Large Jaw Cysts: A Digital Radiographic Analysis of 44 Consecutive Cases. J. Clin. Diagn. Res. 2015; 9: ZC84

25. Kwon YJ, Ko KS, So BK, Kim DH, Jang HS, Kim SH, Lee ES, Lim HK. Effect of Decompression on Jaw Cystic Lesion Based on Three-Dimensional Volumetric Analysis. Medicina (Kaunas). Medicina 2020; 56: 602.

26. Ozdemir H, Toker H, Balc1 H and Ozer H. Effect of ozone therapy on autogenous bone graft healing in calvarial defects: a histologic and histometric study in rats. J Periodont Res 2013; 48: 722-726.

27. Buyuk SK, Ramoglu SI, Sonmez MF. The effect of different concentrations of topical ozone administration on bone formation in orthopedically expanded suture in rats. Eur $\mathbf{J}$ Orthod. 2016; 38(3):281-5.

28. Laçin, N., Kaya, B., Deveci, E., Kadiroğlu, E.T., Aktaş, A., Yalçın, M. and Uysal, E. (2018) Comparative Evaluation of Ozone Treatment in Critical Size Bone Defects Reconstructed with Alloplas-tic Bone Grafts. International Journal of Clinical Medicine, 9, 566-579.

29. Erdemci F, GunaydinY, Sencimen M, Bassorgun I, Ozler M, Oter S, Gulses A, Gunal A. Histomorphometric Evaluation of the Effect of Systemic and Topical Ozone on Alveolar Bone Healing Following Tooth Extraction in Rats. International Journal of Oral and Maxillofacial Surgery. 2014; 43: 777-783.

30. Irban A, Uslu S, Gereli A, Aydinlar EI, Karyemez PE, Luleci $\mathrm{N}$ et al. The effect of ozone therapy on experimental bone fracture healing in rats [abstract]. Proceedings of The World Conference on Ozone Therapy in Medicine, Dentistry and Veterinary. J Ozone Ther. 2019;3(4):29.

31. Kotze M, Bütow KW, Olorunju SA, Kotze HF. Ozone treatment of alveolar bone in the cape chacma baboon does not enhance healing following trauma. J Maxillofac Oral Surg. 2014 Jun;13(2):140-7.

32. Nagayoshi M, Fukuizumi T, Kitamura C, Yano J, Terashita M, Nishihara T. Efficacy of ozone on survival and permeability of oral microorganisms. Oral Microbiol Immunol 2004; 19: 240-6.
33. Abdelhamid A. The Use of Oleozon Gel in the Treatment of Surgically Induced Two-Wall Osseous Defects in Mongrel Dogs. Journal of American Science 2012;8(9): 10171023

34. Holmes J, New technologies in dental care. Dentistry, 2002. 16th May: p. 14. 3-part series.

35. Mohamed ST, Sharara AA, Ragab HR, Zahran NM. Evaluation of Topical Ozone Therapy on Healing of Mandibular Bony Defects. Alexandria Dental Journal. 2015; 40:148152

36. El Hadary AA, Yassin HH, Mekhemer ST, Holmes JC, Grootveld M. Evaluation of the effect of ozonated plant oils on the quality of osseointegration of dental implants under the influence of Cyclosporin A an in vivo study. J Oral Implantol. 2011 Apr;37(2):247-57.

37. Sivalingam VP, Panneerselvam E, Raja KV, Gopi G. Does Topical Ozone Therapy Improve Patient Comfort After Surgical Removal of Impacted Mandibular Third Molar? A Randomized Controlled Trial. J Oral Maxillofac Surg. 2017 Jan;75(1):51. e1-51.

38. Glória JCR, Douglas-de-Oliveira DW, Silva LDA, Falci SGM, Dos Santos CRR. Influence of ozonized water on pain, oedema, and trismus during impacted third molar surgery: a randomized, triple blind clinical trial. BMC Oral Health. 2020 Feb 5;20(1):41.

39. Agrillo, A., Sassano, P., Rinna, C., et al. (2007) Ozone Therapy in Extractive Surgery on Patients Treated with Bisphosphonates. Journal of Craniofacial Surgery, 18, 1068-1070.

40. Pulga A. Oxygen-ozone therapy in dentistry: current applications and future prospects. Ozone Therapy 2018; 3:7968

41. MS Matar I. Clinical and radiographic evaluation the effect of ozone therapy on tissue surrounding implant retained mandibular overdentures. Revista Española de Ozonoterapia. 2016; 6 (1): 51-62

42. Bocci V. Autohemotherapy after treatment of blood with ozone: a reappraisal." The Journal of International Medical Research. 1994; 22: 131-144.

43. Hwang DY, On SW, Song SI. Bone regenerative effect of recombinant human bone morphogenetic protein-2 after cyst enucleation. Maxillofac Plast Reconstr Surg. 2016 26;38(1):22

44. Stübinger S, Sader R, Filippi A. The use of ozone in dentistry and maxillofacial surgery: a review. Quintessence Int. 2006; 37(5): 353-9. 